\title{
Determination of stanozolol and 3'- hydroxystanozolol in rat hair, urine and serum using liquid chromatography tandem mass spectrometry
}

Nawed IK Deshmukh', Gergely Zachar², Andrea Petróczi ${ }^{3}$, Andrea D Székely², James Barker ${ }^{1 *}$ and Declan P Naughton ${ }^{3}$

\begin{abstract}
Background: Anabolic androgenic steroids, such as stanozolol, are typically misused by athletes during preparation for competition. Out-of-competition testing presents a unique challenge in the current anti-doping detection system owing to logistic reasons. Analysing hair for the presence of a prohibited drug offers a feasible solution for covering the wider window in out-of-competition testing. To assist in vivo studies aiming to establish a relationship between drug levels detected in hair, urine and blood, sensitive methods for the determination of stanozolol and its major metabolite 3'-hydroxystanozolol were developed in pigmented hair, urine and serum, using brown Norway rats as a model system and liquid chromatography tandem mass spectrometry (LC-MS/MS).

Results: For method development, spiked drug free rat hair, blood and urine samples were used. The newly developed method was then applied to hair, urine and serum samples from five brown Norway rats after treatment (intraperitoneal) with stanozolol for six consecutive days at $5.0 \mathrm{mg} / \mathrm{kg} /$ day. The assay for each matrix was linear within the quantification range with determination coefficient $\left(r^{2}\right)$ values above 0.995 . The respective assay was capable of detecting $0.125 \mathrm{pg} / \mathrm{mg}$ stanozolol and $0.25 \mathrm{pg} / \mathrm{mg} 3^{\prime}$-hydroxystanozolol with $50 \mathrm{mg}$ hair; $0.063 \mathrm{ng} / \mathrm{mL}$ stanozolol and $0.125 \mathrm{ng} / \mathrm{mL} 3^{\prime}$-hydroxystanozolol with $100 \mu \mathrm{L}$ of urine or serum. The accuracy, precision and extraction recoveries of the assays were satisfactory for the detection of both compounds in all three matrices. The average concentrations of stanozolol and 3'-hydroxystanozolol, were as follows: hair $=70.18 \pm 22.32 \mathrm{pg} / \mathrm{mg}$ and $13.01 \pm$ $3.43 \mathrm{pg} / \mathrm{mg}$; urine $=4.34 \pm 6.54 \mathrm{ng} / \mathrm{mL}$ and $9.39 \pm 7.42 \mathrm{ng} / \mathrm{mL} ;$ serum $=7.75 \pm 3.58 \mathrm{ng} / \mathrm{mL}$ and $7.16 \pm 1.97 \mathrm{ng} / \mathrm{mL}$, respectively.

Conclusions: The developed methods are sensitive, specific and reproducible for the determination of stanozolol and 3'-hydroxystanozolol in rat hair, urine and serum. These methods can be used for in vivo studies further investigating stanozolol metabolism, but also could be extended for doping testing. Owing to the complementary nature of these tests, with urine and serum giving information on recent drug use and hair providing retrospective information on habitual use, it is suggested that blood or urine tests could accompany hair analysis and thus avoid false doping results.
\end{abstract}

Keywords: Anabolic androgenic steroid, Doping, Hair analysis, Urinalysis, Serum analysis, LC-MS/MS

\footnotetext{
* Correspondence: J.Barker@kingston.ac.uk

${ }^{1}$ School of Pharmacy and Chemistry, Kingston University, Penrhyn Road,

Kingston upon Thames, Surrey KT1 2EE, UK

Full list of author information is available at the end of the article
} 


\section{Background}

Laboratory statistics of the World Anti-doping Agency (WADA) show that anabolic-androgenic steroids (AAS) account for around 53.6\% (average from 2005 to 2010) of all adverse analytical findings in sports [1-6]. Among these, stanozolol is one of the most frequently identified AAS. Stanozolol is a synthetic derivative of the male sex hormone testosterone. According to 'The 2013 Prohibition List' of the WADA code, stanozolol belongs to class S1.1a and its use is prohibited both in- and out-ofcompetition [7]. Doping with stanozolol is suspected if the urinary concentration of stanozolol and/or its metabolites exceeds $2 \mathrm{ng} / \mathrm{mL}$ [8]. Three of the major metabolites of stanozolol are reported to be $3^{\prime}$-hydroxystanozolol, $4 \beta$ hydroxystanozolol and 16ß-hydroxystanozolol (Figure 1), which are excreted in urine mainly as glucuronide conjugates [9]. Amongst these, the urinary level of 3'-hydroxystanozolol, post deglucuronidation, is routinely used for screening stanozolol misuse [8-10].

Since stanozolol and 3'-hydroxystanozolol are structurally different from most AAS, they can be more difficult to detect in urine than other AAS [11], and thus require bespoke methods. Depending on the dose administered, once in the body, stanozolol gets rapidly metabolised and the metabolites are generally detected in urine until ca. 6 days [11]. Thus, urinalysis generally fails to determine the long term history of an individual's drug use [12], which is a major hindrance in cases of performance-enhancing drugs used in preparation for competition. Stanozolol, along with other AAS, is a so called 'training drug' which is taken for a prolonged period, typically in cycles, during preparation, in order to obtain the desired performance-enhancing effects $[13,14]$. Furthermore, urinalysis also fails to distinguish between chronic use and single, accidental exposure of drugs [15].

The major elimination and deactivation pathway of AAS and their phase I metabolites is through glucuronide conjugation (phase II metabolism), mainly catalysed by the enzyme UGT2B17, followed by excretion in urine [16-19]. However, inter-individual and inter-ethnic variations in the prevalence of deletion polymorphism in the gene coding of the UGT2B17 enzyme have been reported, which eventually influence the urinary excretion of AAS and potentially lead to false-negative doping results $[20,21]$. It has also been reported that the glucuronidation activity of UGT2B17 and other UGTs towards AAS is inhibited by commonly used anti-inflammatory drugs like diclofenac and ibuprofen, in vitro [22-26]. Common dietary substances such as red wine [27], white tea and green

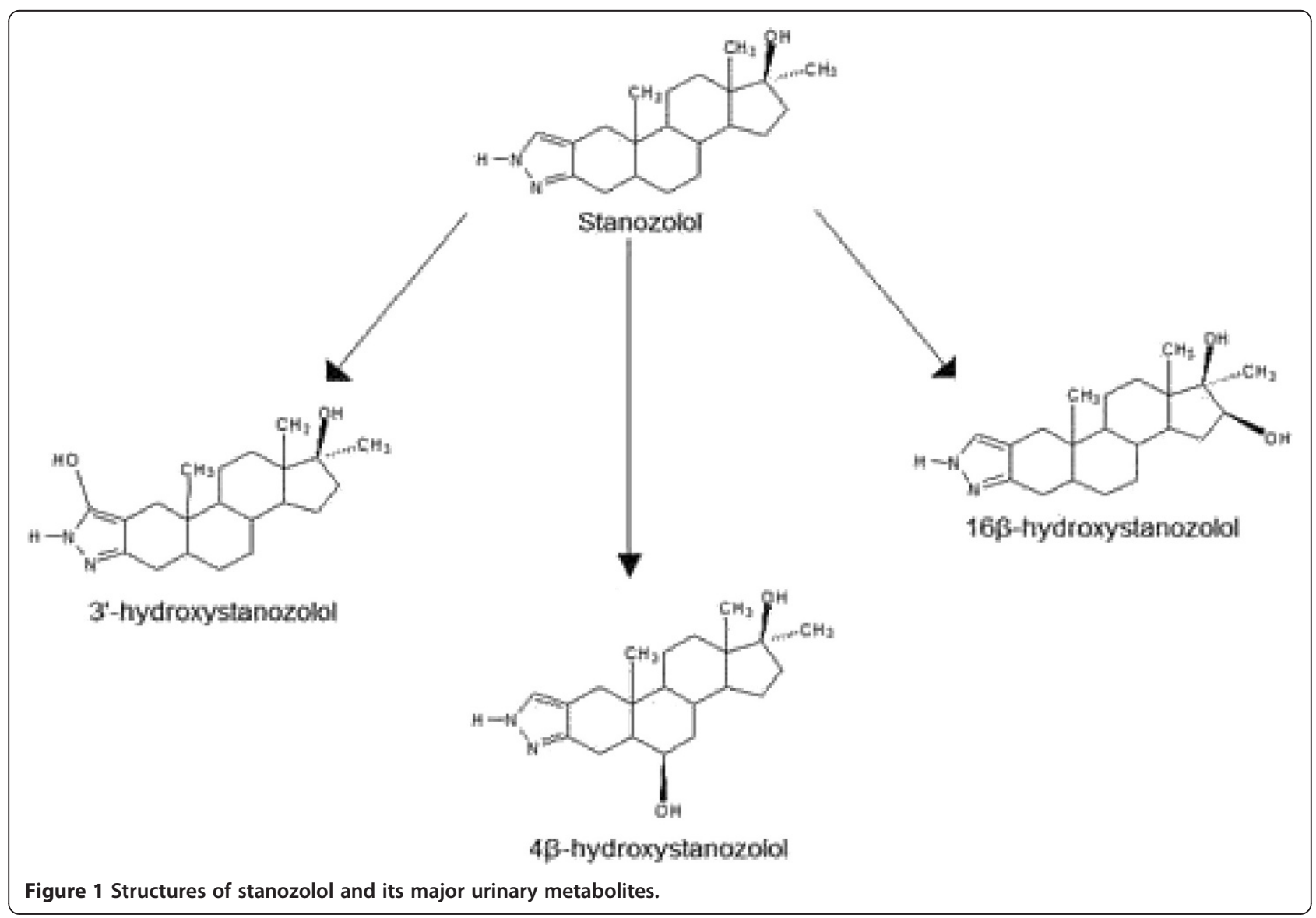


tea [28] have also shown similar inhibitory effects in in vitro studies. Although the inhibitory effect is yet to be examined and reported in vivo, these in vitro results indicate that concomitant use of such over-the-counter medication or common dietary products with AAS may lead to impaired urinary excretion of AAS and their metabolites.

Considering that such genetic and metabolic variations may limit the efficacy of urinalysis in testing doping, it can be suggested that urinalysis, if used as a standalone test, is susceptible to confounding doping results [11-13,16-21]. Owing to the growing number of doping cases with AAS [1-6], there is an ever-increasing need to develop new methods to detect drug doping. The current anti-doping regime can be reinforced by employing additional biological samples like blood and hair analysed in tandem with urine. Since impaired glucuronidation leads to reduction in the urinary excretion rate of AAS, it can be assumed that the levels of unconjugated AAS and their phase I metabolites in the systemic circulation will be elevated and thus higher levels of AAS and their phase I metabolites will be available to get incorporated into hair and other body tissues [21]. Hair analysis has been used in the past for detecting drug use [29-32] as it predominantly favours the direct detection of parent AAS and determines a retrospective history of drug use. Thus, hair analysis and blood analysis [33] can provide complementary information to urinalysis to prevent false doping results.

However, to investigate this option further, in vivo studies are required to establish a relationship between the drug levels detected in hair, urine and blood. To the best of our knowledge, such studies for the determination of stanozolol and its major metabolite, 3'hydroxystanozolol in the three matrices together are, as yet, not reported in the literature. Thus, the aim of this work was to take a step forward by developing liquid-chromatography tandem mass spectrometry (LC-MS/MS) based methods which are capable of determining the concentrations of stanozolol and $3^{\prime}$ hydroxystanozolol in pigmented hair, urine and blood serum samples of stanozolol-treated rats.

In the past, in vivo studies have been reported where administration of a single high dose of stanozolol $(60 \mathrm{mg} / \mathrm{kg})$ to guinea pigs afforded the detection of stanozolol in hair $[34,35]$, whereas it was not possible to detect $3^{\prime}$ hydroxystanozolol [34]. Since, metabolites are generally difficult to detect in hair, it is reasonable to assume that a single-dose treatment may not be sufficient to investigate whether levels of metabolites can be determined in hair. However, multiple doses of stanozolol along with sensitive analytical methods can provide this key information. Thus, as a preliminary step, a 6 day treatment period was used in this study to improve the potential for detecting the metabolites in hair. Athletes typically administer AAS at doses ranging from $3 \mathrm{mg} / \mathrm{kg}$ to $25 \mathrm{mg} / \mathrm{kg}$ to increase muscle mass, which are 10 to 100 fold higher than the therapeutic doses [36]. Thus, in line with previous steroid-abuse rat studies [36-39], the present study was designed with a daily dose of $5.0 \mathrm{mg} /$ $\mathrm{kg}$ for 6 consecutive days, followed by analysing hair, urine and sera samples using newly developed LC-MS/ MS methods.

\section{Experimental}

\section{Chemicals, reagents and consumables}

Reference standards for stanozolol, $3^{\prime}$-hydroxystanozolol, 3'-hydroxystanozolol glucuronide, 3'-hydroxystanozolol D3 and stanozolol D3 were purchased from LGC standards (Teddington, UK). Sodium hydrogen phosphate heptahydrate, sodium phosphate monobasic dihydrate, sodium hydroxide, formic acid, hydrochloric acid, LCMS grade water, acetonitrile, methanol, HPLC grade dichloromethane, pentane, chloroform and ethylacetate were purchased from Sigma Aldrich (Poole, UK). $\beta$ glucuronidase from E. Coli (Cat. No. 03707598001, Lot No. 12438921) was purchased from Roche Diagnostics (Burgess Hill, UK). All chemicals were of analyticalreagent grade and were used without further purification. For the animal experiment, stanozolol, ketamine (2.5\%) and xylazine (Rompun, 2\%) were purchased from Desma (Madrid, Spain), Kőbányai Gyógyszerárugyár (Budapest, Hungary) and Haver-Lockhart laboratories (Kansas, US) respectively. A SB C-18 column $(2.1 \mathrm{~mm}$, $50 \mathrm{~mm}, 1.8 \mu \mathrm{m}$ ) and $0.2 \mu \mathrm{m}$ inline filter was purchased from Agilent (Stockport, UK). Syringe driven $0.2 \mu \mathrm{m}$ PTFE filters were purchased from Millipore (Watford, UK). Silanised glass inserts were purchased from Capital Analytical (Leeds, UK). Silanised, amber, glass vials were purchased from Sigma Aldrich (Poole, UK).

\section{Animals}

Male, brown Norway rats were purchased from Charles River laboratories (Sulzfeld, Germany). Each animal weighed around 280-340 g and was approximately 5 months old. All animals were kept in an animal house located in Semmelweis University, Budapest, Hungary. Animals were housed in groups of three individuals in standard laboratory cages. Rats were kept in a constant room temperature environment with an alternating 12-h light-dark cycle. Food and water were available adlibitum.

\section{Administration of stanozolol and sample collection}

Five rats kept in standard lab cages under 12/12 light/ dark cycle were administered with stanozolol (in saline) intra-peritoneally [34], at a dose of $5.0 \mathrm{mg} / \mathrm{kg} /$ day for six consecutive days. The dose of stanozolol selected was in line with previous steroid studies using rat models [36-39] 
and considered equivalent to levels abused by humans on a milligram per kilogram of body weight basis [36,37]. Hair, urine and blood samples were collected on the $7^{\text {th }}$ day of the study, i.e. one day after stopping the stanozolol treatment.

The growth rate of rat hair was tested prior to the treatment regime by shaving the back of the experimental animals and the sampling protocol was adjusted accordingly.

Urine was collected by gently pressing the abdomen. Blood was taken from the tail vein. Blood samples were left to clot for 45 to 60 minutes and then centrifuged (at $1000 \times \mathrm{g}$ for 10 minutes at room temperature) to harvest serum. Before collecting blood and urine samples, the animals were anaesthetised with a mixture of ketamine and xylazine. Two weeks before the experiment, the entire dorsal surface of the animal was shaved to the skin with an electric shaver and drug-free control hair was collected and preserved. Exactly the same dorsal surface was sampled on the $7^{\text {th }}$ day of the experiment to avoid any diluting effect of the hair grown before the stanazolol treatment period. Drug-free blood and urine samples were also collected before the experiment was initiated. Serum and urine samples obtained were stored at $-80^{\circ} \mathrm{C}$. Hair samples were stored in sealed, clean envelopes at room temperature. The administration of stanozolol and sample collection were conducted under the institutional license of Department of Anatomy, Histology and Embryology, Semmelweis University, Budapest, Hungary in accordance with the EC Council directives on laboratory animals (86/609/EEC). Samples were analysed in Kingston University.

\section{Sample preparation Hair samples}

Hair samples were initially decontaminated by rinsing twice with $2 \mathrm{~mL}$ dichloromethane for two minutes at room temperature. After decontamination, hair samples were allowed to air dry and then pulverised using a ball mill. Fifty milligrams of decontaminated hair powder was incubated with $1 \mathrm{~mL} 1 \mathrm{M}$ sodium hydroxide at $95^{\circ} \mathrm{C}$ for 10-15 minutes in the presence of deuterated internal standards (ISs) stanozolol D3 and 3'-hydroxystanozolol D3. After cooling, the homogenate was neutralised with $1 \mathrm{M}$ hydrochloric acid, followed by addition of $2 \mathrm{~mL}$ of $0.2 \mathrm{M}$ phosphate buffer ( $\mathrm{pH}$ 7.0).

\section{Serum and urine samples}

Serum and urine samples were thawed and vortex mixed. A $100 \mu \mathrm{L}$ aliquot of each was used for analysis.

\section{Enzymatic hydrolysis of glucuronide conjugates}

The enzyme $\beta$-glucuronidase was used for the enzymatic hydrolysis of glucuronide conjugates to determine the total concentration (glucuronide conjugated + unconjugated) of stanozolol and $3^{\prime}$-hydroxystanozolol in each matrix (hair, urine and serum). For this step, and, in a similar manner to the hair samples, the serum and urine samples were also neutralised by mixing with $1 \mathrm{~mL}$ of $0.2 \mathrm{M}$ phosphate buffer $(\mathrm{pH}$ 7.0). The neutralised solutions of hair, serum and urine were hydrolysed by incubation with $50 \mu \mathrm{L}$ of $\beta$ glucuronidase at $50^{\circ} \mathrm{C}$ for two hours in the presence of internal standards [9]. After cooling, the samples were purified by performing liquid-liquid extraction (LLE).

\section{Sample purification}

LLE was carried out by using a mixture of pentane, chloroform and ethylacetate ( $4 \mathrm{~mL}$ in total) in the ratio $3: 2: 1 \mathrm{v} / \mathrm{v} / \mathrm{v}$. The mixture was vortex mixed for 20 seconds and then centrifuged at $4000 \times \mathrm{g}$ for 20 minutes at $4^{\circ} \mathrm{C}$. The organic layer was transferred into a clean, silanised, glass vial and evaporated at $40^{\circ} \mathrm{C}$ using a gentle stream of nitrogen gas. The dried residue was reconstituted with $100 \mu \mathrm{L}$ methanol. The reconstituted solution was filtered through a 0.2 micron PTFE membrane filter, prior to injecting $(3 \mu \mathrm{L})$ into the LC-MS/MS system.

\section{Liquid chromatographic-tandem mass spectrometry}

The analysis of stanozolol and its metabolite $3^{\prime}$ hydroxystanozolol was carried out using an LC-MS/MS system, which comprised of a 1260 infinity LC system (Agilent, Wokingham, UK) coupled to a 6430 triple quadrupole mass spectrometer (Agilent, Wokingham, UK). The LC system comprised of a binary pump, automatic degasser, column heater and 1290 infinity thermostated autosampler. The analytical column used was a SB C-18 column $(2.1 \mathrm{~mm}, 50 \mathrm{~mm}, 1.8 \mu \mathrm{m})$, kept in a column oven at $45^{\circ} \mathrm{C}$. A 0.2 micron inline filter was installed prior to the column to prevent the analytical column from blocking. Mobile phase solvents comprised of water with $0.001 \% \mathrm{v} / \mathrm{v}$ formic acid as solvent $\mathrm{A}$ and 50:50 mixture of acetonitrile and methanol as solvent $\mathrm{B}$. The flow rate of mobile phase through the column was $300 \mu \mathrm{L} / \mathrm{min}$. The gradient flow composition is shown in Table 1.

The mass spectrometer was equipped with an electrospray ionisation (ESI) source, which was operated in positive ion mode. The protonated molecules, $[\mathrm{M}+\mathrm{H}]^{+}$, of stanozolol $(\mathrm{m} / \mathrm{z}$ 329.5), 3'-hydroxystanozolol $(\mathrm{m} / \mathrm{z}$ 345.5), stanozolol D3 $\left(\mathrm{m} / z\right.$ 332.5) and $3^{\prime}$-hydroxystanozolol D3 $(m / z 348.5)$ were used as precursor ions for collision induced dissociation (CID) for MS-MS analysis. The mass spectrometer was operated in multiple reaction monitoring (MRM) mode to monitor the precursor ions and the diagnostic product ions of each analyte and IS. The MRM transitions, collision energies and retention times of each analyte and internal standard are detailed in Table 2. 
Table 1 Chromatograms of stanozolol and 3'-hydroxystanozolol extracted from (a) hair, (b) urine and (c) serum at LLOQ concentration levels

\begin{tabular}{ccc}
\hline LC run time (minutes) & Solvent A Water (0.001\% formic acid) & Solvent B Acetonitrile: methanol (50:50) \\
\hline 0 & 60 & 40 \\
1 & 60 & 40 \\
2 & 15 & 85 \\
5 & 0 & 100 \\
6 & 0 & 100 \\
7 & 60 & 40 \\
15 & 60 & 40 \\
\hline
\end{tabular}

For the optimum ionisation of analytes, the following mass spectrometric conditions were applied: capillary voltage, $4000 \mathrm{~V}$; drying gas temperature, $325^{\circ} \mathrm{C}$; drying gas flow rate, $10 \mathrm{~L} / \mathrm{min}$; nebulising gas pressure, 35 psi and fragmentor voltage of $125 \mathrm{~V}$. The mass spectrometric parameters were optimised using the Masshunter optimizer software (version B.03.01). The LC-MS/MS system was controlled by the Masshunter workstation software (LC/MS data acquisition, version B.03.01).

\section{Method validation}

The validation of the analytical methods was performed according to the Food and Drug Administration (FDA) guidelines [40], by determining accuracy, precision, lower limits of quantification (LLOQ), lower limits of detection (LLOD), linearity, selectivity, and extraction recoveries $[41,42]$. Drug-free rat hair, urine and serum samples were used for method development and validation. Samples for calibration curves were prepared by spiking known amounts of stanozolol, 3'-hydroxystanozolol and ISs (stanozolol D3 and 3'-hydroxystanozolol D3) to drug-free hair, urine and serum. Quality control (QC) samples were prepared similarly at three concentration levels (for each matrix) distributed over the linear range. Calibration curves were prepared for each matrix by plotting the analyte to IS ratio against the known concentrations of analyte in each sample. The analyte to IS ratio for each analyte was obtained by dividing the peak area of analyte by the peak area of the IS. Samples for calibration curves and quality controls were treated in a way similar to unknowns. The linearity of the method was investigated by using linear regression analysis.

The accuracy of each assay was determined by analysing QC samples at three concentration levels in replicates $(\mathrm{N}=6$, per concentration level) and comparing the mean calculated values with the respective nominal concentration values. Intra-day precision was determined by measuring 6 replicates per concentration level, on the same day. Inter-day precision was assessed by analysing 6 replicates per concentration level, on three consecutive days. Intra-day and inter-day precision of the method was characterised in terms of relative standard deviation (RSD, \%). The limits of acceptable variability were set at $15 \%$ for all the concentrations, except at LLOQ, for which $20 \%$ was accepted. LLOD was defined as the lowest concentration of the analyte which gave a peak response equivalent to three times the background noise [i.e. signal to noise ratio $(S / N) \geq 3$ ]. LLOQ was defined as the lowest amount of analyte which gave a peak response with a $S / N \geq 10$ and which could be measured with adequate precision and accuracy (RSD less than $20 \%$ and an inaccuracy $\pm 20 \%$ ) [40].

The selectivity of the method was determined by analysing the drug-free samples of hair, urine and serum in replicates and confirming the absence of any detectable peaks at the retention times of stanozolol, 3'-hydroxystanozolol and ISs. The extraction recovery for each analyte was determined at three concentration levels by replicate analysis $(\mathrm{N}=6)$ of blank matrices (urine, serum and hair) spiked with known concentrations of analytes and ISs and

Table 2 Retention times, MRM transitions and collision energies of stanozolol, 3'-hydroxystanozolol, stanozolol D3 and 3'-hydroxystanozolol D3

\begin{tabular}{lccc}
\hline Compounds & Retention time $(\mathbf{m i n})$ & MRM transitions & Collision energy (eV) \\
\hline Stanozolol & 6.0 & $329.5>81.1$ & 50 \\
& & $329.5>121.1$ & 46 \\
3'-Hydroxystanozolol & 5.6 & $345.5>97.1$ & 50 \\
& & $345.5>121.1$ & 42 \\
Stanozolol D3 & 6.1 & $332.2>81.2$ & 50 \\
3'-Hydroxystanozolol D3 & 5.8 & $348.5>97.1$ & 50 \\
\hline
\end{tabular}


then extracted as described above. The analyte to internal standard peak area ratios obtained after extraction were then compared with analyte to internal standard peak area ratios of standard solutions prepared in methanol at the same final concentrations. To determine matrix effects, blank hair, urine and serum samples from different animals were extracted as described above. In order to consider only the matrix effect and not losses during the extraction procedure, the blank extracts were spiked with known concentrations of analytes and ISs after the extraction step, followed by analysis. The resulting peak areas of stanozolol, 3'-hydroxystanozolol and ISs were then compared with the peak areas of standard solutions of stanozolol, 3'-hydroxystanozolol and ISs at the same theoretical concentrations.

\section{Results and discussion Method development}

Both stanozolol and 3'-hydroxystanozolol were detected and quantified on the basis of their retention time and MRM transitions (Table 2). The most abundant product ions that were monitored for stanozolol were $\mathrm{m} / \mathrm{z} 81.1$ and 121.1, whereas for $3^{\prime}$-hydroxystanozolol, the most abundant product ions that were monitored were $\mathrm{m} / \mathrm{z}$ 97.1 and 121.1. Figure 2 represents the product ions mass spectra (full scan) of stanozolol and 3'-hydroxystanozolol. Operating the mass spectrometer in MRM mode enhanced the method selectivity, sensitivity and specificity. Stanozolol D3 and 3'-hydroxystanozolol D3 were used as internal standards for stanozolol and $3^{\prime}$-hydroxystanozolol respectively. Internal standards were used to compensate for any: i) ionisation suppression, ii) variations in the instrument response from injection to injection and iii) loss of analytes during sample preparation.

Use of different mobile phase solvents was investigated. For instance, use of water as solvent $\mathrm{A}$ in combination with methanol or acetonitrile or a mixture of methanol and acetontrile (50:50) as solvent B was examined. Different gradient and isocratic mobile phase compositions were investigated. Addition of formic acid $(0.001 \% \mathrm{v} / \mathrm{v}$, $0.01 \% \mathrm{v} / \mathrm{v}$ and $0.1 \% \mathrm{v} / \mathrm{v}$ ) to solvent $\mathrm{A}$ and/or solvent $\mathrm{B}$ was also investigated. Optimum sensitivity and excellent peak shapes for all analytes and ISs were obtained when water with formic acid $(0.001 \% \mathrm{v} / \mathrm{v})$ was used as solvent $\mathrm{A}$ and a mixture of acetonitrile and methanol (50:50) was used as solvent B under the gradient conditions shown in Table 1. It was observed that when formic acid was added to solvent $\mathrm{A}$ and/or solvent $\mathrm{B}$ at concentrations $\geq 0.01 \% \mathrm{v} / \mathrm{v}$, there was a drastic reduction in the sensitivity of all analytes and ISs (up to 50\%). However, when formic acid was added only to water (solvent A) at a concentration of $0.001 \% \mathrm{v} / \mathrm{v}$, there was no effect on the sensitivity and peak shapes.
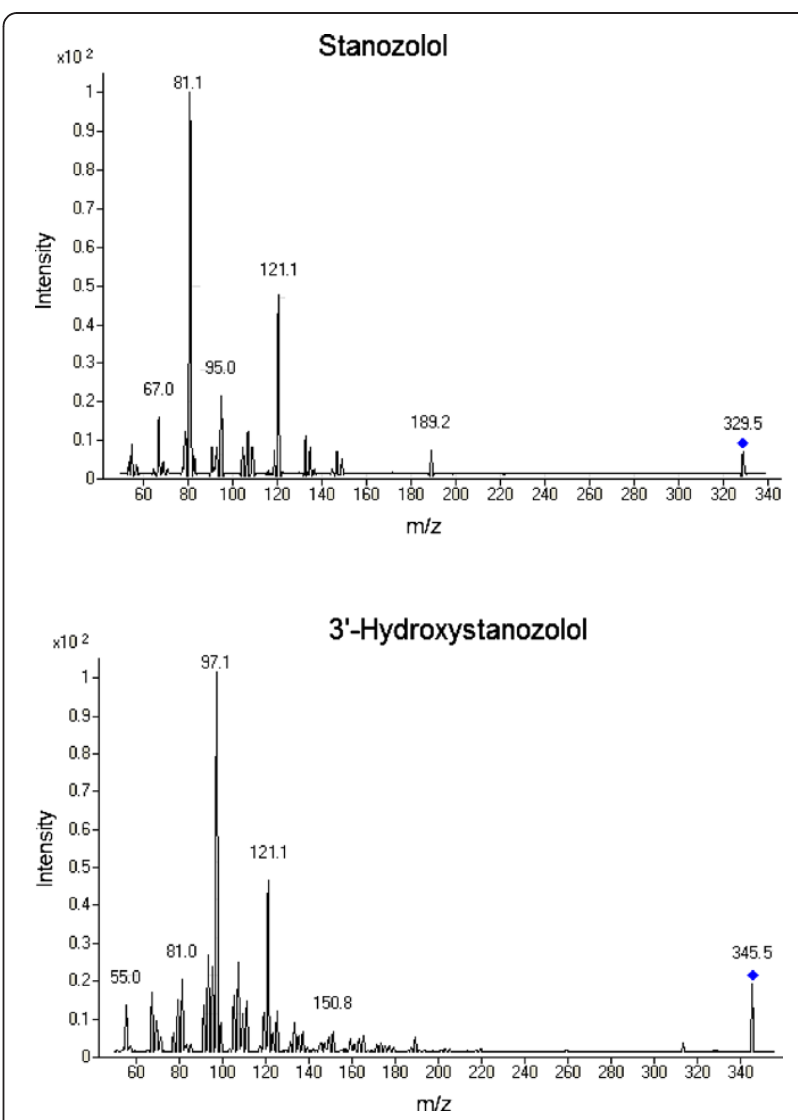

Figure 2 Product ion mass spectra (full scan) of stanozolol and 3'-hydroxystanozolol.

For hair analysis, alkali digestion was employed for the extraction of drugs from hair matrix. Alkali digestion ensures complete dissolution of the hair matrix and hence it is generally known to give good recoveries of drugs entrapped in the hair matrix. However, a potential drawback of complete dissolution of hair is that the components of hair matrix in solution may interfere with the analysis. Thus, to reduce the unwanted matrices that may affect the analysis, sample purification was carried out using LLE. The extraction efficiencies of different solvents like pentane, hexane, chloroform, ethyl acetate and ethanol, and their combinations were investigated. It was found that a mixture of pentane, chloroform and ethyl acetate in the ratio 3:2:1 v/v/v facilitated maximum recovery of analytes and ISs. Also, owing to the hair decontamination step employed (using dichloromethane), no external interferences were observed. The LLE step employed was also efficient for the extraction of stanozolol, 3'-hydroxystanozolol and ISs from the urine and serum samples. Under the analytical conditions employed, there were no matrix interferences that affected the analysis of stanozolol and $3^{\prime}$-hydroxystanozolol in hair, urine and serum. The enzymatic hydrolysis of glucuronide conjugates of stanozolol and 3'-hydroxystanozolol was 


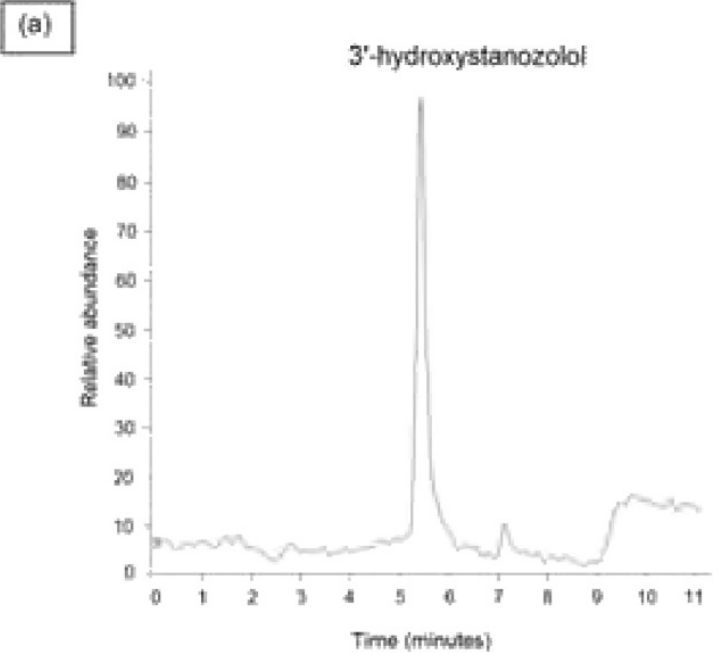

(b)
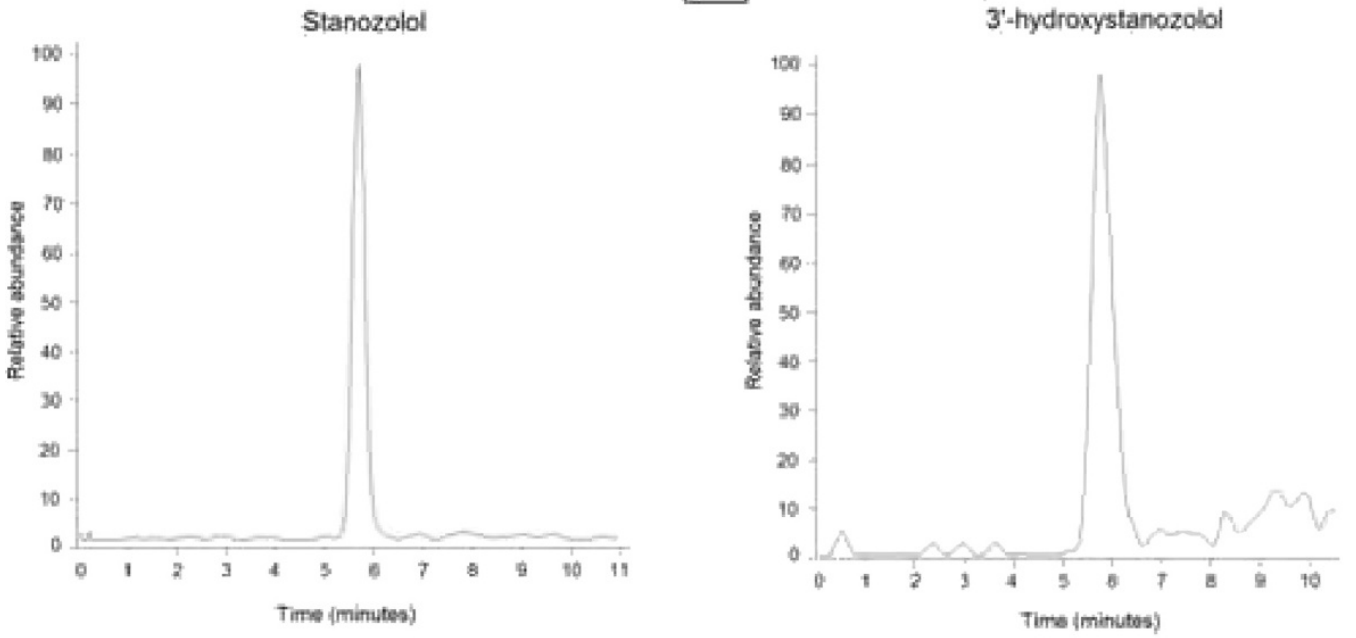

(c)
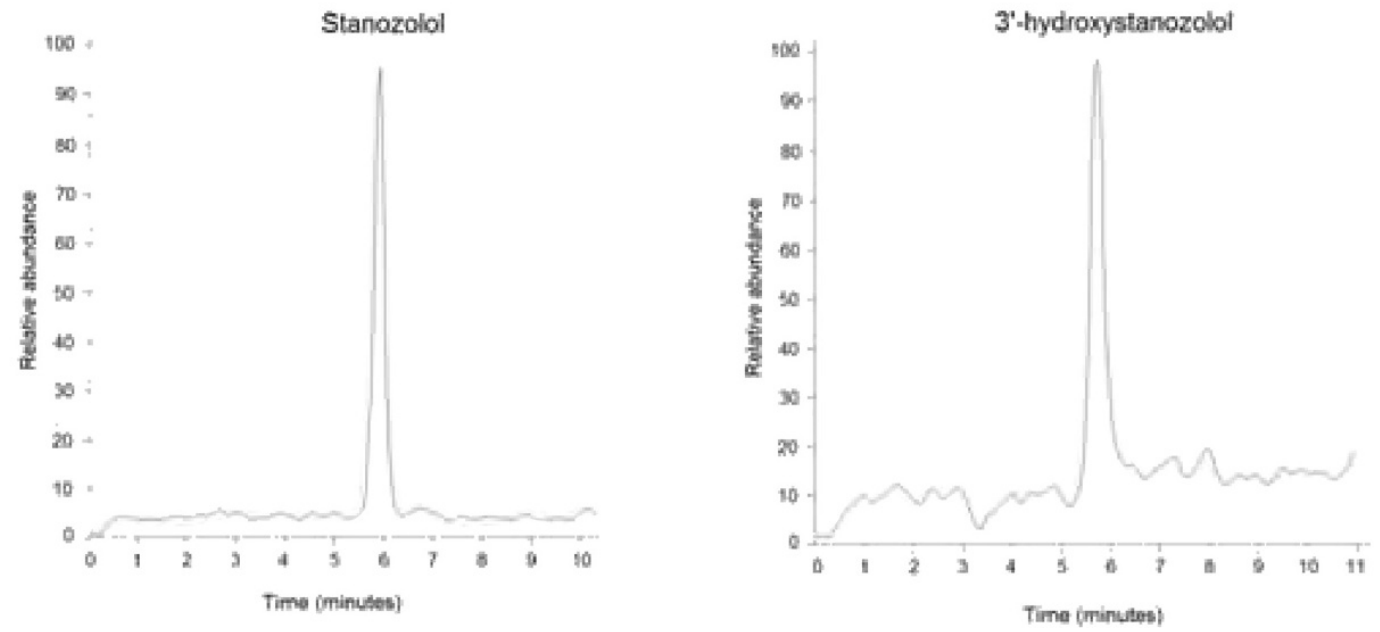

Figure 3 Chromatograms of stanozolol and $3^{\prime}$-hydroxystanozolol extracted from (a) hair, (b) urine and (c) serum at LLOQ concentration levels. 
carried out. This ensured that the total concentration (glucuronide conjugated plus unconjugated) of stanozolol and 3 '-hydroxystanozolol could be determined in each matrix [9]. The conditions employed for enzymatic hydrolysis step (incubation temperature, time and $\mathrm{pH}$ ) were optimised using 3'-hydroxystanozolol glucuronide. Complete hydrolysis of the glucuronide conjugate was achieved when the $\mathrm{pH}$ of the sample solution was adjusted to 7 , followed by incubation with $\beta$-glucuronidase ( $50 \mu \mathrm{L}$ ) at $50^{\circ} \mathrm{C}$ for 2 hours.

\section{Method validation}

The validation results are within the limits set by the FDA guidelines [40]. The methods were selective and specific for unambiguous determination of stanozolol and 3'hydroxystanozolol in all three matrices. Suppression or enhancement of analyte ionisation owing to co-eluting components of matrices was not observed. Excellent peak shape was achieved for stanozolol, $3^{\prime}$-hydroxystanozolol, stanozolol D3 and 3'-hydroxystanozolol D3. Figure 3 represents chromatograms of stanozolol and $3^{\prime}$-hydroxystanozolol extracted from hair, urine and serum at LLOQ concentration levels. Typical calibration curves of stanozolol and 3'hydroxystanozolol in all three matrices are provided in Additional file 1.

\section{Hair}

The assay for hair analysis was linear in the range 0.5 $400 \mathrm{pg} / \mathrm{mg}$ for both stanozolol and 3'-hydroxystanozolol. The determination coefficient $\left(\mathrm{r}^{2}\right)$ values were found to be higher than 0.9986 for all calibration curves. The method was capable of detecting (LLOD) stanozolol and 3'hydroxystanozolol in hair at concentrations as low as $0.125 \mathrm{pg} / \mathrm{mg}$ and $0.25 \mathrm{pg} / \mathrm{mg}$ respectively when $c a .50 \mathrm{mg}$ hair was processed. The LLOQ level of both stanozolol and 3'-hydroxystanozolol was found to be $0.5 \mathrm{pg} / \mathrm{mg}$. The accuracy, intra-day precision and inter-day precision results of the assay are detailed in Table 3. The extraction recoveries of both compounds (at three concentration levels) from hair are presented in Table 4.
Table 4 Extraction recovery results of stanozolol and 3'-hydroxystanozolol from hair

\begin{tabular}{lcc}
\hline Compounds & $\begin{array}{c}\text { Concentration } \\
(\mathbf{p g} / \mathbf{m g})\end{array}$ & $\begin{array}{c}\text { \% Extraction } \\
\text { recovery } \\
\mathbf{( N = 6 )}\end{array}$ \\
\hline Stanozolol & $0.5(\mathrm{LLOQ})$ & 100.84 \\
& 2.5 & 103.53 \\
3-Hydroxystanozolol & 10 & 105.39 \\
& $0.5(\mathrm{LLOQ})$ & 88.51 \\
& 2.5 & 107.99 \\
& 10 & 102.64 \\
\hline
\end{tabular}

\section{Urine}

The assay for urinalysis was linear in the range 0.125 $25 \mathrm{ng} / \mathrm{mL}$ for stanozolol and $0.25-25 \mathrm{ng} / \mathrm{mL}$ for $3^{\prime}$ hydroxystanozolol. The determination coefficient $\left(\mathrm{r}^{2}\right)$ values were found to be higher than 0.9959 for all runs. The method was capable of detecting (LLOD) stanozolol and $3^{\prime}$-hydroxystanozolol at concentrations as low as $0.063 \mathrm{ng} / \mathrm{mL}$ and $0.125 \mathrm{ng} / \mathrm{mL}$ urine respectively, when only $100 \mu \mathrm{L}$ aliquot of urine was processed. The LLOQ levels of stanozolol and 3'-hydroxystanozolol were found to be $0.125 \mathrm{ng} / \mathrm{mL}$ and $0.25 \mathrm{ng} / \mathrm{mL}$ urine respectively. Table 5 summarises the accuracy, intra-day precision and inter-day precision results of the assay. The extraction recoveries from urine at three concentration levels are presented in Table 6 .

\section{Serum}

The serum assay showed good linearity within the quantification range $0.25-100 \mathrm{ng} / \mathrm{mL}$ for both stanozolol and 3'-hydroxystanozolol, with determination coefficient $\left(\mathrm{r}^{2}\right)$ values higher than 0.9981 . The method was capable of detecting (LLOD) stanozolol and 3'-hydroxystanozolol in serum at concentrations as low as $0.063 \mathrm{ng} / \mathrm{mL}$ and $0.125 \mathrm{ng} / \mathrm{mL}$ respectively when only $100 \mu \mathrm{L}$ aliquot of serum was processed. The LLOQ level of both stanozolol and $3^{\prime}$-hydroxystanozolol was found to be $0.25 \mathrm{ng} / \mathrm{mL}$.

Table 3 Accuracy, intra-day precision and inter-day precision of the assay for detecting stanozolol and 3'-hydroxystanozolol in rat hair

\begin{tabular}{|c|c|c|c|c|c|}
\hline \multirow[t]{2}{*}{ Compounds } & \multirow[t]{2}{*}{ Concentration (pg/mg) } & \multirow[t]{2}{*}{ Level } & \multicolumn{2}{|c|}{ Precision RSD (\%) } & \multirow[t]{2}{*}{ Accuracy $(\%)$} \\
\hline & & & Intra-day & Inter-day & \\
\hline \multirow[t]{3}{*}{ Stanozolol } & 2.5 & Low & 3.4 & 2.8 & 105.0 \\
\hline & 20 & Medium & 1.5 & 1.3 & 103.4 \\
\hline & 100 & High & 1.2 & 2.8 & 100.7 \\
\hline \multirow[t]{3}{*}{ 3'-Hydroxystanozolol } & 2.5 & Low & 1.5 & 4.1 & 97.3 \\
\hline & 20 & Medium & 3.6 & 3.4 & 101.9 \\
\hline & 100 & High & 3.8 & 5.3 & 100.5 \\
\hline
\end{tabular}


Table 5 Accuracy, intra-day precision and inter-day precision of the assay for detecting stanozolol and 3'-hydroxystanozolol in rat urine

\begin{tabular}{|c|c|c|c|c|c|}
\hline \multirow[t]{2}{*}{ Compounds } & \multirow[t]{2}{*}{ Concentration (ng/mL) } & \multirow[t]{2}{*}{ Level } & \multicolumn{2}{|c|}{ Precision RSD (\%) } & \multirow[t]{2}{*}{ Accuracy $(\%)$} \\
\hline & & & Intra-day & Inter-day & \\
\hline \multirow[t]{3}{*}{ Stanozolol } & 0.5 & Low & 10.4 & 6.3 & 90.6 \\
\hline & 2.5 & Medium & 4.6 & 7.0 & 105.6 \\
\hline & 5 & High & 4.1 & 4.0 & 111.4 \\
\hline \multirow[t]{3}{*}{ 3'-Hydroxystanozolol } & 0.5 & Low & 4.9 & 6.2 & 89.7 \\
\hline & 2.5 & Medium & 7.1 & 5.0 & 109.2 \\
\hline & 5 & High & 6.4 & 5.1 & 104.2 \\
\hline
\end{tabular}

The accuracy, intra-day precision and inter-day precision results of the assay are detailed in Table 7 . The extraction recoveries are presented in Table 8.

\section{Application of the method to real samples}

The developed methods were employed for determining the total (glucuronide-conjugated plus un-conjugated) concentration of stanozolol and its metabolite 3 -hydroxystanozolol in rat hair, urine and serum samples. Table 9 represents the average concentrations (three replicates) of stanozolol and $3^{\prime}$-hydroxystanozolol in hair, urine and serum samples of each rat. The average concentrations of stanozolol and 3 -hydroxystanozolol in rat hair were found to be $70.18 \pm 22.32 \mathrm{pg} / \mathrm{mg}$ and $13.01 \pm 3.43 \mathrm{pg} / \mathrm{mg}$ respectively. The average ratio of concentrations of stanozolol to $3^{\prime}$-hydroxystanozolol in hair was found to be $5.38 \pm$ 0.93 . Variations observed in the concentration of stanozolol and 3 '-hydroxystanozolol amongst individual animals could be owing to differences in their metabolic pattern. Furthermore, difference in the amount of water consumed by animals can also lead to variations in the levels of drugs in their body. The results indicate that stanozolol gets preferentially incorporated in hair relative to its metabolite 3 -hydroxystanozolol. These findings are in agreement with previous reports [32]. In the past, researchers have found it difficult to detect $3{ }^{\prime}$ hydroxystanozolol in hair. Cirimile et al. reported the detection of stanozolol in scalp hair of a bodybuilder

Table 6 Extraction recovery results of stanozolol and 3'-hydroxystanozolol from urine

\begin{tabular}{lcc}
\hline Compounds & $\begin{array}{c}\text { Concentration } \\
(\mathbf{n g} / \mathbf{m L})\end{array}$ & $\begin{array}{c}\text { \% Extraction } \\
\text { recovery } \\
\mathbf{( N = 6 )}\end{array}$ \\
\hline Stanozolol & $0.125(\mathrm{LLOQ})$ & 107.87 \\
& 2.5 & 111.77 \\
3-Hydroxystanozolol & 10 & 109.64 \\
& $0.25(\mathrm{LLOQ})$ & 91.44 \\
& 2.5 & 107.92 \\
& 10 & 111.82 \\
\hline
\end{tabular}

who declared to be a regular user of stanozolol [43]. However, 3'-hydroxystanozolol was not detectable in hair under their analytical conditions. Similarly, in another study carried out by Shen et al., stanozolol was detectable in guinea pig hair after administering stanozolol at a single high dose of $60 \mathrm{mg} / \mathrm{kg}$, whereas, 3'-hydroxystanozolol was not detectable [34]. However, the method presented here was capable of detecting stanozolol and 3'-hydroxystanozolol in rat hair after administering stanozolol for 6 days at a dose of $5.0 \mathrm{mg} / \mathrm{kg} /$ day that is considered equivalent to those levels abused by athletes [36-39]. Thieme et al. have reported a case where both stanozolol and $3^{\prime}$ hydroxystanozolol were detectable in the hair of a bodybuilder using gas chromatography high resolution mass spectrometry (GC-HRMS), after sample derivatisation [44]. In the past GC-MS and GC-HRMS have been frequently employed for the detection of AAS [43-46]. The major disadvantage of such technique is that it requires a laborious and expensive sample derivatisation step. Generally, the derivatives are unstable and susceptible to thermal decomposition during analysis, thus affecting the reproducibility of the method. In contrast, LC-MS/MS normally does not require any additional derivatisation step. Thus, LC-MS/MS can be considered as a more economical and feasible approach for analysing AAS [29,30,47].

In urine, the average concentrations of stanozolol and 3 -hydroxystanozolol were found to be $4.34 \pm 6.54 \mathrm{ng} / \mathrm{mL}$ and $9.39 \pm 7.42 \mathrm{ng} / \mathrm{mL}$ respectively. The average urinary ratio of stanozolol concentration to $3^{\prime}$-hydroxystanozolol concentration was found to be $0.37 \pm 0.32$. The results indicate that the urinary concentrations of stanozolol are comparatively lower than $3^{\prime}$-hydroxystanozolol, as expected. However, in serum the average ratio of concentrations of stanozolol to 3 '-hydroxystanozolol was found to be $1.09 \pm 0.37$. Thus, suggesting that both compounds can be detected in serum at similar concentration levels and with equal ease.

The results suggest that the newly developed LC-MS/ MS based methods are capable of detecting and quantifying total concentration (glucuronide conjugated plus 
Table 7 Accuracy, intra-day precision and inter-day precision of the assay for detecting stanozolol and 3'-hydroxystanozolol in rat serum

\begin{tabular}{|c|c|c|c|c|c|}
\hline \multirow[t]{2}{*}{ Compounds } & \multirow[t]{2}{*}{ Concentration (ng/mL) } & \multirow[t]{2}{*}{ Level } & \multicolumn{2}{|c|}{ Precision RSD (\%) } & \multirow[t]{2}{*}{ Accuracy $(\%)$} \\
\hline & & & Intra-day & Inter-day & \\
\hline \multirow[t]{3}{*}{ Stanozolol } & 1.25 & Low & 4.4 & 3.0 & 111.0 \\
\hline & 10 & Medium & 1.4 & 1.6 & 108.4 \\
\hline & 50 & High & 1.7 & 1.4 & 90.4 \\
\hline \multirow[t]{3}{*}{ 3'-Hydroxystanozolol } & 1.25 & Low & 4.3 & 6.4 & 98.0 \\
\hline & 10 & Medium & 3.5 & 3.9 & 102.3 \\
\hline & 50 & High & 4.8 & 5.3 & 91.9 \\
\hline
\end{tabular}

unconjugated) of stanozolol and its major metabolite, $3^{\prime}$ hydroxystanozolol in hair, urine and serum samples of brown Norway rats after administering stanozolol for 6 days at a dose $(5.0 \mathrm{mg} / \mathrm{kg} /$ day $)$, and this is in line with steroid studies using rat models [36-39]. Future studies may expand the stanozolol treatment period to 3 or more weeks to mimic typical athlete use, along with experimenting with different stanozolol doses and conditions. These newly developed methods can assist in vivo studies designed to further investigate the metabolism of stanozolol. Urinalysis can provide information on whether UGT substrates/inhibitors and deletion polymorphism in the UGT2B17 gene reduce the glucuronidation rate (phase II metabolism) of stanozolol and $3^{\prime}$ hydroxystanozolol, as impaired glucuronidation has been reported to reduce the urinary concentrations of AAS. It can be assumed that, owing to compromised urinary excretion, the serum levels of unconjugated stanozolol and 3 hydroxystanozolol can get elevated [21]. Thus, potentially greater amounts of stanozolol and 3'-hydroxystanozolol will be available to get incorporated in hair. Hence, these methods can assist in investigating the potential application of hair analysis and serum analysis to provide complementary information when the urinary excretion of stanozolol and 3'-hydroxystanoozlol is impaired.

Table 8 Extraction recovery results of stanozolol and 3'-hydroxystanozolol from serum

\begin{tabular}{lcc}
\hline Compounds & $\begin{array}{c}\text { Concentration } \\
\mathbf{( n g} / \mathbf{m L})\end{array}$ & $\begin{array}{c}\text { \% Extraction } \\
\text { recovery } \\
\mathbf{( N = 6 )}\end{array}$ \\
\hline Stanozolol & $0.25(\mathrm{LLOQ})$ & 113.24 \\
& 2.5 & 101.92 \\
3-Hydroxystanozolol & 10 & 109.42 \\
& $0.25(\mathrm{LLOQ})$ & 95.36 \\
& 2.5 & 111.03 \\
& 10 & 105.29 \\
\hline
\end{tabular}

\section{Conclusions}

To our knowledge, the detection of stanozolol and 3'hydroxystanozolol in rat hair, urine and serum at such low concentration levels using LC-MS/MS, has been reported here for the first time. Using the newly developed methods presented here, future research can carry out in vivo studies to further investigate stanozolol

Table 9 Concentrations of stanozolol and 3'-hydroxystanozolol in rat hair, urine and serum samples

\begin{tabular}{|c|c|c|c|c|}
\hline Matrix & Animal & Stanozolol & $\begin{array}{c}3^{\prime}- \\
\text { Hydroxystanozolol }\end{array}$ & Ratio \\
\hline \multicolumn{5}{|c|}{ Hair (pg/mg) } \\
\hline & 1 & $46.57 \pm 0.17$ & $10.96 \pm 0.15$ & 4.25 \\
\hline & 2 & $47.25 \pm 1.07$ & $9.13 \pm 0.12$ & 5.18 \\
\hline & 3 & $82.58 \pm 2.67$ & $16.92 \pm 0.37$ & 4.88 \\
\hline & 4 & $77.98 \pm 1.03$ & $11.72 \pm 0.30$ & 6.65 \\
\hline & 5 & $96.54 \pm 1.02$ & $16.29 \pm 0.07$ & 5.93 \\
\hline & Mean & $\begin{array}{c}70.18 \pm \\
22.32\end{array}$ & $13.01 \pm 3.43$ & $\begin{array}{c}5.38 \pm \\
0.93\end{array}$ \\
\hline \multicolumn{5}{|c|}{ Jrine (ng/mL) } \\
\hline & 1 & $5.20 \pm 0.09$ & $13.54 \pm 0.43$ & 0.38 \\
\hline & 2 & $0.20 \pm 0.01$ & $0.36 \pm 0.02$ & 0.56 \\
\hline & 3 & $0.17 \pm 0.02$ & $5.07 \pm 0.01$ & 0.03 \\
\hline & 4 & $0.70 \pm 0.01$ & $8.51 \pm 2.41$ & 0.08 \\
\hline & 5 & $15.41 \pm 0.08$ & $19.49 \pm 0.22$ & 0.79 \\
\hline & Mean & $4.34 \pm 6.54$ & $9.39 \pm 7.42$ & $\begin{array}{c}0.37 \pm \\
0.32\end{array}$ \\
\hline \multicolumn{5}{|c|}{ erum (ng/mL) } \\
\hline & 1 & $5.91 \pm 0.00$ & $7.25 \pm 0.29$ & 0.82 \\
\hline & 2 & $4.69 \pm 0.01$ & $7.62 \pm 0.27$ & 0.62 \\
\hline & 3 & $13.01 \pm 0.01$ & $8.76 \pm 0.67$ & 1.49 \\
\hline & 4 & $5.24 \pm 0.06$ & $3.81 \pm 0.27$ & 1.38 \\
\hline & 5 & $9.90 \pm 0.03$ & $8.38 \pm 0.22$ & 1.18 \\
\hline & Mean & $7.75 \pm 3.58$ & $7.16 \pm 1.97$ & $\begin{array}{c}1.09 \pm \\
0.37\end{array}$ \\
\hline
\end{tabular}


metabolism, thus making an important step towards understanding of the array of factors that may confound urinalysis results. Also, these methods can be extended by analysing human hair, urine and serum samples in tandem to provide a pattern of drug use and this can be useful for testing doping with stanozolol and other commonly abused AAS. Hair can provide retrospective information on an individual's drug use and this can be used in out-of-competition testing. However, information of current drug-use, if important, can be obtained by urine and blood serum analyses. Thus, when the three tests are used in combination, useful information on an individual's drug use can be obtained and false doping results can be prevented.

\section{Additional file}

Additional file 1: Figure S1. Calibration curves of stanozolol and $3^{\prime}$ hydroxystanozolol in (a) hair, (b) urine and (c) serum.

\section{Abbreviations}

AAS: Anabolic androgenic steroids; CID: Collision induced dissociation FDA: Food and Drug Administration; GC-HRMS: Gas chromatography high resolution mass spectrometry; GC-MS: Gas chromatography mass spectrometry; ISs: Internal standards; LC-MS/MS: Liquid chromatography tandem mass spectrometry; LLE: Liquid-liquid extraction; LLOQ: Lower limit of quantification; LLOD: Lower limit of detection; MRM: Multiple reaction monitoring; QC: Quality control; RSD: Relative standard deviation; UGT2B17: Uridine diphosphate-glucuronosyltransferase 2B17; WADA: World Anti-Doping Agency.

\section{Competing interests}

The authors declare that they have no competing interests.

\section{Authors' contribution}

$A P, J B$ and DPN initiated the study. GZ, NIKD and AP designed the study. GZ and ADSz conducted the animal experiments. The method development and sample analyses were conducted by NIKD who prepared the draft paper. All authors contributed to data analyses and to finalising the manuscript. All authors have read and approved the final version.

\section{Acknowledgement}

The project was partially supported by the Kingston University's summer project grant.

\section{Author details}

${ }^{1}$ School of Pharmacy and Chemistry, Kingston University, Penrhyn Road, Kingston upon Thames, Surrey KT1 2EE, UK. ²Department of Anatomy, Histology and Embryology, Semmelweis University, Budapest IX, Tüzoltó utca $58 \mathrm{H}-1450$, Hungary. ${ }^{3}$ School of Life Sciences, Kingston University, London, UK.

Received: 18 October 2012 Accepted: 18 December 2012

Published: 22 December 2012

\section{References}

1. The World Anti-Doping Agency: Laboratory statistics. 2005. http://www. wada-ama.org/Documents/Science_Medicine/Anti-Doping_Laboratories/ WADA_LaboStatistics_2005.pdf, [accessed on 20.09.2012]

2. The World Anti-Doping Agency: Laboratory statistics. 2006. http://www. wada-ama.org/Documents/Science_Medicine/Anti-Doping_Laboratories/ WADA_LaboStatistics 2006.pdf, [accessed on 20.09.2012]

3. The World Anti-Doping Agency: Laboratory statistics. 2007. http://www wada-ama.org/Documents/Science_Medicine/Anti-Doping_Laboratories/ WADA_LaboStatistics_2007.pdf, [accessed on 20.09.2012]
4. The World Anti-Doping Agency: Laboratory statistics. 2008. http://www. wada-ama.org/Documents/Science_Medicine/Anti-Doping_Laboratories/ WADA_LaboStatistics_2008.pdf, [accessed on 20.09.2012]

5. The World Anti-Doping Agency: Laboratory statistics. 2009. http:// www.wada-ama.org/Documents/Science_Medicine/AntiDoping_Laboratories/Lab_Statistics/

WADA_2009_LaboratoryStatisticsReport_Final.pdf, [accessed on 20.09.2012]

6. The World Anti-Doping Agency: Laboratory statistics. 2010. http://www. wada-ama.org/Documents/Resources/Statistics/Laboratory_Statistics/ WADA_2010_Laboratory_Statistics_Report.pdf, [accessed on 20.09.2012]

7. The World Anti-Doping Agency: The prohibition list. 2013. http://www.wadaama.org/Documents/World_Anti-Doping_Program/WADP-Prohibited-list/ 2013/WADA-Prohibited-List-2013-EN.pdf, [accessed on 08.10.2012]

8. The World Anti-Doping Agency: WADA technical document-TD2013MRPL. http://www.wada-ama.org/Documents/World_Anti-Doping_Program/ WADP-IS-Laboratories/Technical_Documents/WADA-TD2013MRPLMinimum-Required-Performance-Levels-v1-2012-EN.pdf, [accessed on 20.09.2012]

9. Pozo OJ, Eenoo PV, Deventer K, Lootens L, Grimalt S, Sancho JV, Hernández F, Meuleman P, Leroux-Roels G, Delbeke FT: Detection and structural investigation of metabolites of stanozolol in human urine by liquid chromatography tandem mass spectrometry. Steroids 2008, 74(10-11):837-852

10. World Anti-Doping Agency: WADA technical document-TD2010MRPL. http:// www.wada-ama.org/documents/world_anti-doping_program/wadp-islaboratories/wada_td2010mrplv1.0_minimum\%20required\%20performance \%20levels_sept\%2001\%202010_en.pdf, [accessed on 20.09.2012]

11. Mateus-Avois L, Mangin P, Saugy M: Use of ion trap gas chromatographymultiple mass spectrometry for the detection and confirmation of $3^{\prime}$-hydroxystanozolol at trace levels in urine for doping control. $J$ Chromatogr B 2005, 816(1-2):193-201.

12. Kintz $P$, Cirimele V, Sachs $H$, Jeanneau T, Ludes B: Testing for anabolic steroids in hair from two bodybuilders. Forensic Sci Int 1999, 101:209-216.

13. Graham MR, Davies B, Grace FM, Kicman A, Baker JS: Anabolic steroid use patterns of use and detection of doping. Sports Med 2008, 38:505-525

14. Sjöqvist F, Garle M, Rane A: Use of doping agents, particularly anabolic steroids, in sports and society. Lancet 2008, 371:1872-1882.

15. De Cock KJS, Delbeke FT, Van Eenoo P, Desmet N, Roels K: Detection and determination of anabolic steroids in nutritional supplements. J Pharm Biomed Anal 2001, 25:843-852.

16. Turgeon D, Carrier JB, Chouinard S, Belanger A: Glucuronidation activity of the UGT2B17 enzyme toward xenobiotics. Drug Metab Dispos 2003, 31:670-676.

17. Belanger A, Pelletier G, Labrie F, Barbier O, Chouinard S: Inactivation of androgens by UDP-glucuronosyltransferase enzymes in humans. Trends Endocrinol Metab 2003, 14(10):473-479.

18. Hum DW, Belanger $A$, Levesque $E$, Barbier $O$, Beaulieu M, Albert $C$, Vallee $M$, Guillemette C, Tchernof A, Turgeon D, Dubois S: Characterization of UDPglucuronosyltransferases active on steroid hormones. J Ster Biochem Mol Biol 1999, 69:413-423.

19. You L: Steroid hormone biotransformation and xenobiotic induction of hepatic steroid metabolizing enzymes. Chem Biol Interact 2004, 147:233-246.

20. Schulze JJ, Lundmark J, Garle M, Skilving I, Ekström L, Rane A: Doping test results dependent on genotype of uridine diphospho-glucuronosyl transferase $2 \mathrm{~B} 17$, the major enzyme for testosterone glucuronidation. J Clin Endocrinol Metab 2008, 93(7):2500-2506.

21. Deshmukh N, Petróczi A, Barker J, Székely AD, Hussain I, Naughton DP: Potentially harmful advantage to athletes: a putative connection between UGT2B17 gene deletion polymorphism and renal disorders with prolonged use of anabolic androgenic steroids. Subst Abuse Treat Prev Policy 2010, 5(7). http://dx.doi.org/10.1186/1747-597X-5-7.

22. Sten T, Finel M, Ask B, Rane A, Ekström L: Non-steroidal antiinflammatory drugs interact with testosterone glucuronidation. Steroids 2009, 74:971-977.

23. Thuyne WV, Delbeke FT: Declared use of medication in sports. Clin J Sport Med 2008, 18:143-147. 
24. Tsitsimpikou C, Tsiokanos A, Tsarouhas K, Schamasch P, Fitch K, Valasiadis D, Jamurtas A: Medication use by athletes at the Athens 2004 summer Olympic games. Clin J Sport Med 2009, 19(1):33-38.

25. Warden SJ: Prophylactic misuse and recommended use of non-steroidal anti-inflammatory drugs by athletes. Br J Sport Med 2009, 43:548-549.

26. Skarberg K, Nyberg F, Engstrom I: Multisubstance use as a feature of addiction to anabolic-androgenic steroids. Eur Addict Res 2009 15(2):99-106.

27. Jenkinson C, Petroczi A, Naughton DP: Red wine and components flavonoids inhibit UGT2B17 in vitro. Nutrition 2012, 11. http://dx.doi.org/ 10.1186/1475-2891-11-67.

28. Jenkinson C, Petroczi A, Barker J, Naughton DP: Dietary green and white teas suppress UDP-glucuronosyltransferase UGT2B17 mediated testosterone glucuronidation. Steroids 2012, 77(6):691-695.

29. Deshmukh N, Barker J, Petroczi A, Naughton DP: Detection of testosterone and epitestosterone in human hair using liquid chromatographytandem mass spectrometry. J Pharm Biomed Anal 2012, 67-68:154-158.

30. Deshmukh N, Hussain I, Barker J, Petroczi A, Naughton DP: Analysis of anabolic steroids in human hair using LC-MS/MS. Steroids 2010, 75(10):710-714.

31. Kintz $P$, Cirimele V, Dumestre-Toulet $V$, Ludes B: Doping control for nandrolone using hair analysis. J Pharm Biomed Anal 2001, 24:1125-1130.

32. Poelmans S, De Wasch K, De Brabander HF, Van De Wiele M, Courtheyn D, van Ginkel LA, Sterk SS, Delahaut P, Dubois $M$, Schilt R, Nielen $M$, Vercammen J, Impens S, Stephany R, Hamoir T, Pottie G, Van Poucke C, Van Peteghem C: Analytical possibilities for the detection of stanozolol and its metabolites. Anal Chim Acta 2002, 473:39-47.

33. Pablo JS, Sánchez-Baeza F, Marco MP: Simultaneous immunochemical detection of stanozolol and the main human metabolite, 3-hydroxystanozolol, in urine and serum samples. Anal Biochem 2008, 376:221-228.

34. Shen $M$, Xiang $P$, Yan $H$, Shen $B$, Wang M: Analysis of anabolic steroids in hair: time courses in guinea pigs. Steroids 2009, 74:773-778.

35. Shen $M$, Yan $H$, Xiang $P$, Shen $B$ : Simultaneous determination of anabolic androgenic steroids and their esters in hair by LC-MS-MS. Chromatographia 2009, 70:1381-1386.

36. de Almeida Chuffa LG, de Souza RB, Frei F, de Fátima Paccola Mesquita S, Camargo IC: Nandrolone decanoate and physical effort: histological and morphometrical assessment in adult rat uterus. Anat Rec 2011, 294:335-341.

37. Pieretti S, Mastriota M, Tucci P, Battaglia G, Trabace L, Nicoletti F, Scaccianoce S: Brain nerve growth factor unbalance induced by anabolic androgenic steroids in rat. Med Sci Sports Exerc 2012, doi:10.1249/ MSS.0b013e31826c60ea.

38. Breuer ME, McGinnis MY, Lumia AR, Possidente BP: Aggression in male rats receiving anabolic androgenic steroids: effects of social and environmental provocation. Horm Behav 2001, 40(3):409-418.

39. Matrisciano F, Modafferi AM, Togna Gl, Barone Y, Pinna G, Nicoletti F Scaccianoce S: Repeated anabolic androgenic steroid treatment causes antidepressant-reversible alterations of the hypothalamic-pituitaryadrenal axis, BDNF levels and behavior. Neuropharmacology 2010, 58 (7):1078-1084

40. Food and drug act: Bioanalytical method validation. [http://www.fda.gov/ downloads/Drugs/. . ./Guidances/ucm070107.pdf], [accessed on 20.09.2012]

41. Peters FT, Drummer OH, Musshoff F: Validation of new methods. Forensic Sci Int 2007, 165:216-224.

42. Matuszewski BK, Constanzer ML, Chavez-Eng CM: Strategies for the assessment of matrix effect in quantitative bioanalytical methods based on HPLC-MS/MS. Anal Chem 2003, 75:3019-3030.

43. Cirimele $V$, Kintz $P$, Ludes $B$ : Testing of the anabolic stanozolol in human hair by gas chromatography-negative ion chemical ionization mass spectrometry. J Chromatogr B 2000, 740(2):265-271.
44. Thieme D, Grosse J, Sachs H, Mueller RK: Analytical strategy for detecting doping agents in hair. Forensic Sci Int 2000, 107(1-3):335-345.

45. Höld KM, Wilkins DG, Crouch DJ, Rollins DE, Maes RA: Detection of stanozolol in hair by negative ion chemical ionization mass spectrometry. J Anal Toxicol 1996, 20(6):345-349.

46. Min S, Ping X, Baohua S, Jun B, Mengye W: Physiological concentrations of anabolic steroids in human hair. Forensic Sci Int 2009, 184:32-36.

47. He C, Li S, Liu H, Li K, Liu F: Extraction of testosterone and epitestosterone in human urine using aqueous two-phase systems of ionic liquid and salt. J Chromatogr A 2005, 1082(2):143-149.

\section{doi:10.1186/1752-153X-6-162}

Cite this article as: Deshmukh et al:: Determination of stanozolol and $3^{\prime}$ hydroxystanozolol in rat hair, urine and serum using liquid chromatography tandem mass spectrometry. Chemistry Central Journal 2012 6:162.

\section{Publish with ChemistryCentral and every scientist can read your work free of charge \\ "Open access provides opportunities to our colleagues in other parts of the globe, by allowing anyone to view the content free of charge." W. Jeffery Hurst, The Hershey Company. \\ - available free of charge to the entire scientific community \\ - peer reviewed and published immediately upon acceptance \\ - cited in PubMed and archived on PubMed Central \\ - yours - you keep the copyright \\ Submit your manuscript here: \\ http://www.chemistrycentral.com/manuscript/<smiles>c1ccccc1</smiles> \\ Chemistry Central}

